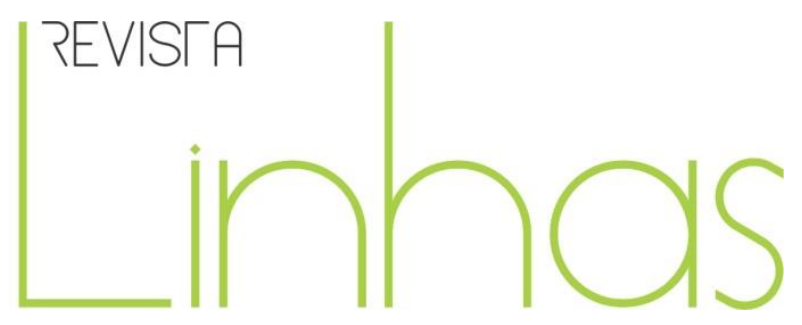

\title{
É possível ensinar gênero na escola? Análise de experiências de formação em gênero, sexualidade e diversidades em Santa Catarina
}

\section{Resumo}

Este trabalho reflete sobre desafios da sensibilização pedagógica aos temas de gênero e sexualidade a partir de diferentes experiências de formação de professoras/es e estudantes de diferentes níveis de ensino (pré-escola, fundamental, médio e universitário) realizadas nos cursos de aperfeiçoamento e especialização "Gênero e Diversidade na Escola" (GDE/SECADI), no "Projeto Papo Sério" (NIGS/PROEXT), em cursos vinculados ao Programa Pró-Equidade de Gênero e no Programa Iniciação à Docência em Ciências Sociais (PIBID/CAPES) desenvolvidos entre 2009 e 2016, sob nossa coordenação, na UFSC e na UFFS. Sabemos que escolas e universidades são espaços contraditórios. Nelas se reproduzem hierarquias e assimetrias, promovem-se violências ou compactua-se com elas, silencia-se e se insiste em modelos normativos. Todavia, é também nesses espaços que se tem produzido um importante movimento de transformação social, marcado pela busca crescente de formação de professores/as e estudantes nas temáticas de gênero e sexualidade. Assim, um dos principais desafios da formação em gênero e sexualidade é sensibilizar as pessoas a uma perspectiva crítica sobre as relações sociais naturalizadas pela dominação, exclusão e discriminação. Essa sensibilização se dá, via de regra, pela "descoberta" das pessoas em formação de situações de seus cotidianos e de relações pessoais marcadas por violências das mais diferentes ordens: dupla ou tripla jornada de trabalho, relações conjugais e familiares hierárquicas, sexismo, misoginia, capacitismo, racismo, homo-lesbo-transfobia. Refletiremos, a partir de exemplos concretos, sobre nossa experiência de formação de professoras/es e estudantes nesse campo, mostrando as potencialidades dessa formação para a transformação das relações sociais marcadas por diferentes violências.

Palavras-chave: Formação. Gênero. Sexualidade. Santa Catarina.

\author{
Tânia Welter \\ Universidade Federal de Santa \\ Catarina - UFSC - \\ Florianópolis/SC - Brasil \\ taniawelter@yahoo.com.br \\ Miriam Pillar Grossi \\ Universidade Federal de Santa \\ Catarina - UFSC - \\ Florianópolis/SC - Brasil \\ miriamgrossi@gmail.com
}

\section{Para citar este artigo:}

WELTER, Tânia; GROSSI, Miriam Pillar. É possível ensinar gênero na escola? Análise de experiências de formação em gênero, sexualidade e diversidades em Santa Catarina. Revista Linhas. Florianópolis, v. 19, n. 39, p. 123-145, jan./abr. 2018. 


\title{
Is it possible to teach gender diversity in schools? An analysis of teaching experiences involving gender, sexuality and diversity topics in Santa Catarina
}

\begin{abstract}
This work discusses the challenges of raising educational awareness involving gender and sexuality topics based on different experiences of educating teachers and students at different levels (kindergarten, elementary school, high school and tertiary levels). These activities took place in different training courses such as: the "Gender and Diversity in School" course (GDE/SECADI); in the "Serious Talk Project" (NIGS/PROEXT); in courses pertaining to both the "Pro Gender Equity Program" and the "Teaching of Social Sciences' Training Program" sponsored by PIBID/CAPES. These activities were coordinated by us and took place between 2009 and 2016 at both the UFSC and the UFFS. We understand schools and universities as contradictory spaces where: hierarchies and asymmetries are reproduced, violences are promoted or condoned, people are silenced, and normative models continue to be reinforced. However, these spaces have also been stage to an important social transformation movement, characterized by an increasing in training activities which educate teachers and students in topics related to Gender and Sexuality. Thus, one of the main challenges in Gender and Sexuality Education activities is to raise people's awareness and to promote a more critical analysis of the existing social relations which are turned into the norm by domination, exclusion and discrimination. Based on concrete examples, we will debate our experiences in educating teachers and students in this area, pointing out the potentialities of these training activities for the transformation of certain social relationships marked by different violences.
\end{abstract}

Keywords: Training of Teachers and Students. Gender. Sexuality. State of Santa Catarina. 


\section{Introdução}

Sabemos que a escola, mais do que um lugar para a transmissão de conhecimentos, é espaço para encontro, socializações e trocas de saberes. Embora o Estado Democrático de Direito assegure o reconhecimento das diversidades, observamos que as escolas públicas brasileiras estão, muitas vezes, mais comprometidas com práticas discriminatórias, violências e com a promoção ou manutenção de desigualdades e assimetrias entre as pessoas.

Diante desse quadro, fazemos as seguintes perguntas: A escola pública que conhecemos, em que estudamos ou trabalhamos reconhece ou discrimina as diferenças? É possível falar de cultura de ódio quando falamos em educação? O que motiva os discursos odiosos? É possível pensar na escola como o espaço para questionamento de padrões hegemônicos, estímulo para práticas inclusivas e respeitosas e reflexões teóricometodológicas?

Este texto tem o objetivo de refletir antropologicamente, a partir de exemplos concretos, sobre nossa experiência de formação de professoras/es e estudantes no campo de gênero e sexualidade, mostrando as potencialidades dessa formação para a transformação das relações sociais marcadas por diferentes violências.

\section{O direito à diferença}

Inicialmente é importante localizar nossa perspectiva teórica a respeito de gênero, sexualidade e diversidades. Sabemos que são conceitos polissêmicos, reapropriados de forma particular em cada momento político. Esclarecemos, portanto, que as experiências que relatamos aqui, foram desenvolvidas durante o período no qual o Partido dos Trabalhadores esteve no poder no Brasil (mandatos Lula - 2003-2010 e Dilma Rousseff 2011-2016). Neste período, foram desenvolvidas importantes políticas públicas no campo da Educação, com foco na formação e sensibilização para as temáticas de gênero, sexualidade e diversidades. Políticas construídas e desenvolvidas pela articulação entre ativistas de movimentos sociais, pesquisadoras/es vinculadas/os a núcleos de pesquisa nas universidades e agentes do Estado, a partir de demandas produzidas nas Conferências Nacionais de Políticas para Mulheres, Educação, LGBT, Questões Étnico- 
raciais, Direitos Humanos. Neste contexto político, a perspectiva de gênero dizia respeito ao reconhecimento de que diferenças entre homens e mulheres são construtos sociais que produzem e reproduzem desigualdades e não raro, violências para sustentar a dominação masculina. Neste sentido, ao propor uma abordagem das relações de gênero, é inevitável entender a sexualidade ocidental como moldada pelo heterocentrismo, forma de conceber como unicamente válidas as relações afetivas e sexuais entre sujeitos de gêneros diferentes. Nesta perspectiva construtivista do gênero e da sexualidade, é fundamental abordar a temática do poder desigual entre homens e mulheres, hétero e homossexuais, pessoas cis e pessoas trans, pessoas com e sem deficiência. As experiências que apresentamos aqui são fruto desta perspectiva, que tem como foco, a mudança nos padrões heteronormativos de gênero.

Este texto está inspirado na perspectiva intercultural e no reconhecimento das diferenças que nos atravessam como humanos ${ }^{1}$. Essa perspectiva nos coloca enormes desafios; um deles é reconhecer as limitações dos processos históricos e culturais e promover críticas a eles. Para Antônio Moreira e Michelle Câmara (2008) e Vera Candau (2008), as diferenças são construídas social e culturalmente, muitas vezes, para legitimar privilégios, sendo, portanto, atravessadas por relações de poder, preconceitos e discriminações e recorrentemente hierarquizadas. Reconhecer e valorizar as diferenças deveria levar ao movimento de repúdio das desigualdades, da visão binária e dicotômica entre o "nós", considerado como normal, superior, exemplo a ser seguido, e o "outro", visto como anormal, inferior, estranho, impuro.

Para que o diálogo entre os grupos e pessoas ocorra, é necessário reconhecer o “outro", afirmam esses autores. Essa é a ação primeira para enfrentar e superar as assimetrias entre os grupos, incluir as diferenças e desvelar o "daltonismo cultural”"

Miguel Arroyo afirmou ${ }^{3}$, no entanto, que a interculturalidade é uma ação de diálogo que deve ocorrer entre iguais. Na prática, afirma, isso nunca ocorreu, nunca

\footnotetext{
${ }^{1}$ Sobre essa perspectiva ver, entre outros, Reinaldo Fleuri (2012 e 1998), Luiz Lopes (2008) e Vera Candau (2008).

${ }^{2}$ Ideia desenvolvida por Vera Candau (2008) para se referir à incapacidade de muitas pessoas de discernir toda a gama de tonalidades que compõem o arco-íris ou de reconhecer a diversidade cultural que nos rodeia.
} 
houve diálogos interculturais em nossa história, especialmente se observarmos o contexto da América Latina. Essa é muito mais uma história de dominação de uma cultura sobre a outra, de subalternização, genocídios e culturicídios do que de diálogos culturais. A superação desse modelo social poderia ocorrer através da educação formal, que deveria promover o reconhecimento e reflexão sobre essa história brutal, cruel e violenta contra os povos e as pessoas.

No campo das políticas públicas de Educação, durante os governos petistas (20032016), prevaleceu o conceito de diferença vinculado às desigualdades étnico-raciais. $E$ foi no bojo das mobilizações de movimentos negros que foram desenvolvidas inúmeras políticas públicas de "respeito às diferenças".

Diante disso, nos perguntamos: como a escola pública se posiciona diante das diferenças? Mais do que respostas, queremos propor aqui uma reflexão, trazer inquietações e subsidiar iniciativas na superação das diferentes formas de violências e nos silenciamentos diante de ações discriminatórias em torno das identidades sexuais e de gênero não normativas ${ }^{4}$.

Guacira Louro se pergunta ${ }^{5}$ se dá para falar de ódio quando falamos em educação. Fazendo uma reflexão sobre motivações e consequências das palavras/discursos em torno da sexualidade e da identidade de gênero, ela diz que as palavras não têm significado fixo, dizem respeito a uma coletividade e muitas vezes carregam uma perspectiva depreciativa. É o caso de termos como "sapatão”, "bicha”, “veado" e outros, recorrentemente utilizados para insultar, xingar e depreciar uma pessoa ou grupo. Os agentes dos discursos de ódio muitas vezes não são seus autores, mas os reproduzem,

\footnotetext{
${ }^{3}$ Em comunicação feita no Painel de Abertura do II SICDES, II CONSUDI e V CCER: "Educação Intercultural e Territórios Contestados Latino-Americanos: contextos, dinâmicas e desafios", realizado no dia 14 de maio de 2014.

${ }^{4}$ Para Miriam Grossi, gênero remete à construção cultural coletiva dos atributos de masculinidade e feminilidade e sexualidade ao campo das práticas e sentimentos ligados à atividade sexual dos indivíduos (GROSSI, 2010, p. 12). Os papéis de gênero e sexuais são invenções sociais, se constituem a partir de múltiplos discursos (reguladores, normalizadores, produtores de verdades) e são recorrentemente orientados pela perspectiva binária (sexo-gênero) e pela matriz heterossexual. Nesse modelo, a identidade trans e a homossexualidade são rejeitadas porque não estão em conformidade com as normas sociais (JUNQUEIRA, 2009; MEYER, 2009; LOURO, 1997, 2003).

${ }^{5}$ Durante conferência de encerramento do VII Congresso Internacional de Estudos sobre a Diversidade Sexual e de Gênero da Associação Brasileira de Estudos da Homocultura - ABEH, evento realizado na cidade de Rio Grande, entre 7 a 9 de maio 2014.
} 
fortalecem e carregam sua carga negativa para o futuro. Louro expressa preocupação de muitas educadoras no Brasil com as consequências dos discursos odiosos na escola. Como lidar com eles? Tentar calar? Punir? Muitos organismos, especialmente o Estado e a jurisprudência, optam pela punição ${ }^{6}$. Mas calar um sujeito garantirá o silenciamento do discurso odioso, que é coletivo? Muitos movimentos sociais e intelectuais acreditam que a mudança pode ocorrer a partir da positivação de termos ou da explicitação das sexualidades não hegemônicas.

\section{Preconceito, etnocentrismo, estereótipo, discriminação}

O que motiva esses discursos? Alguns conceitos antropológicos como etnocentrismo, estereótipo, discriminação podem auxiliar-nos nessa reflexão. Renato Queiroz (1997) e Sérgio Carrara et al. (2009) sugerem que etnocentrismo consiste em julgar, a partir de padrões culturais próprios, como "certo" ou “errado", "feio" ou "bonito", "normal” ou "anormal”, os comportamentos e as formas de ver o mundo das outras pessoas e povos, muitas vezes desqualificando suas práticas e até negando sua humanidade. O etnocentrismo se relaciona com o conceito de estereótipo, que consiste na generalização e atribuição de valor (negativos ou positivos) a algumas características de um grupo, reduzindo-o a essas características e definindo os "lugares de poder" a serem ocupados. "É uma generalização de julgamentos subjetivos feitos em relação a um determinado grupo, impondo-lhe o lugar de inferior e o lugar de incapaz no caso dos estereótipos negativos" (CARRARA et al., 2009, p. 24-25).

O estereótipo funciona como um carimbo que alimenta os preconceitos, ao se definir, a priori, quem são e como são as pessoas. O etnocentrismo é a base do estereótipo e do preconceito, que, como diz a palavra, é algo que vem antes (pré) do conhecimento (conceito). Recorrentemente se define "o lugar" daquela pessoa ou grupo antes mesmo de conhecê-la. Outro significado da palavra "conceito" é “juízo”. Nesse caso, preconceito seria um (pré)juízo ou prejuízo para quem o sofre e também para quem

\footnotetext{
${ }^{6}$ Os questionamentos de Theophilos Rifiotis (2015), Guita Debert e Marcella Oliveira (2007) sobre o excesso de judicialização das relações sociais ou uso exagerado do recurso da judicialização na resolução dos conflitos domésticos são fundamentais nessa discussão. São fundamentais também, as reflexões de Esther Grossi (2009) e Esther Grossi e Jussara Bordin (2009) sobre a importância da agressividade e do conflito na aprendizagem.
} 
o exerce, pois seu (pré)conceito o impede de entrar em contato com o outro e/ou a outra.

Se o estereótipo e o preconceito estão no campo das ideias, a discriminação é uma ação, uma atitude (QUEIROZ, 1997). "É a atitude de discriminar, de negar oportunidades, de negar acesso, de negar humanidade. Nessa perspectiva, a omissão e a invisibilidade também são consideradas atitudes, também se constituem em discriminação" (CARRARA et al., 2009, p. 26).

\section{Escola: espaço para reconhecimento ou discriminação das diferenças?}

Muitas pesquisas ressaltam que muitas escolas e profissionais da educação desconsideram os conhecimentos das pessoas em formação, suas diferenças de cor de pele, de gênero ou de desejo sexual, além de não ouvir seus corpos ou interesses ${ }^{7}$. Para Luiz Lopes (2008), essa postura contribui para a naturalização de ideais corpóreos como branquitude, de gênero como masculino e de sexualidade como heterossexualidade.

Recorrentemente a escola atua como uma das principais agências de “(re)produção e organização de indivíduos sociais de forma generificada, sexualizada e racializada" (LOPES, 2008, p. 127). Essa reprodução está na contramão da vida fora da escola, que acentua as diferenças, ou dos avanços de diversos movimentos sociais, como feministas, antirracistas e de gays, lésbicas, bissexuais, transexuais e transgêneros.

Luiz Lopes (2008) observou na escola uma contradição entre três discursos: de profissionais da educação, de pessoas em formação e das políticas públicas. Os primeiros são legitimados na escola e geralmente refletem as tradições em que são formados ${ }^{8}$. Os discursos das pessoas em formação são elaborados a partir das práticas sociais. Já os discursos das políticas públicas educacionais se baseiam em políticas de identidades. Para contribuir com a superação das contradições de discursos no contexto escolar, esse autor

\footnotetext{
7 Claudia Fonseca (1994) e Ana Luiza Carvalho da Rocha (2011). Essa discussão nos aproxima de Sherry Ortner (2007, p. 46). Para essa autora, indivíduos, pessoas ou sujeitos são sempre agentes, não autônomos, individuais, heroicos ou livres, mas "envolvidos na multiplicidade de relações sociais em que estão enredados e jamais podendo agir fora dela."

${ }^{8}$ Para Marília Carvalho (2008, p. 120): "A falta de clareza e de discussão crítica sobre os objetivos curriculares e consequentemente os critérios de avaliação também contribuem para que as professoras lancem mão de repertórios e valores pessoais, marcados pelos preconceitos de classe, raça e gênero presentes no senso comum."
} 
propõe que se parta das teorias queer. A partir dessa perspectiva teórica, seria possível questionar normatividades em relação à sexualidade, problematizar a naturalização da vida social e os ideais que persistem na escola apagando e homogeneizando corpos e discursos como parte de uma lógica monocultural ${ }^{9}$.

Para esse autor, a ideia não seria defender as chamadas minorias (gays, lésbicas), mas recusar qualquer essência para a sexualidade, mostrar a "natureza fabricada" da hétero e da homossexualidade. Essa abordagem ajudaria a ver que os sentidos que nos rodeiam são construções e invenções, e essas, portanto, podem ser refeitas, (re)escritas e reinventadas. Ajudaria, ainda, a duvidar das certezas e verdades sedimentadas na escola.

Diferentemente dessa perspectiva, muitas pesquisas constataram que tratamentos preconceituosos, medidas discriminatórias, ofensas, constrangimentos, ameaças e agressões físicas ou verbais têm sido uma constante na vida escolar e profissional de crianças, jovens e adultos, especialmente daqueles que se afastam dos ideais corpóreos de branquitude, do papel social de gênero ${ }^{10}$, da orientação sexual heterossexual, entre outros ${ }^{11}$. Desde cedo, essas pessoas veem-se às voltas com o que se denominou de "pedagogia do insulto", constituída de piadas, brincadeiras, jogos, apelidos, insinuações e expressões desqualificantes ${ }^{12}$. Rogério Junqueira (2009, p. 17) considera esses comportamentos como "[...] poderosos mecanismos de silenciamento e de dominação simbólica”. Por meio dessa pedagogia, estudantes aprendem a ser hostis

\footnotetext{
9 Para esse autor, a lógica do "somos todos iguais" só foi possível porque anulou os atravessamentos identitários na vida social, inclusive descorporificando estudantes e professores/as.

${ }^{10}$ Para Miriam Grossi (2010), há uma diferença entre papel e identidade de gênero. Enquanto o primeiro se refere ao comportamento social que é associado ao sexo biológico (fêmea ou macho) em determinada cultura, o segundo "remete à constituição do sentimento individual de identidade" e "a um conjunto de convicções pelas quais se considera socialmente o que é masculino ou feminino" (GROSSI, 2010, p. 8). Jaqueline de Jesus (2012) define da seguinte forma a construção dessa identidade de gênero: as pessoas cisgênero ou "cis" são aquelas que se identificam com o gênero que lhes foi atribuído ao nascerem. Ressalta que "[...] há uma diversidade na identificação das pessoas com algum gênero, e com o que se considera próprio desse gênero" (2012, p. 10). Entre aqueles que não se identificam com o gênero social, "[...] há quem se considere transgênero, como uma categoria à parte das pessoas travestis e transexuais. Existem ainda as pessoas que não se identificam com qualquer gênero, não há consenso quanto a como denominá-las. Alguns utilizam o termo queer; outros, a antiga denominação 'andrógino', ou reutilizam a palavra transgênero" (JESUS, 2012, p. 10).

${ }^{11}$ Sobre isto, ver Virginia Nunes (2015) e Arthur Novo (2015).

${ }_{12}$ Para Guacira Louro (2003, p. 29), "meninos e meninas aprendem, também desde muito cedo, piadas e gozações, apelidos e gestos para dirigirem àqueles e àquelas que não se ajustam aos padrões de gênero e de sexualidade admitidos na cultura em que vivem."
} 
aos homossexuais, transgêneros, negros, frequentadores de religiões não hegemônicas, entre outros, antes mesmo de saber a que se referem. A invisibilidade e a "pedagogia do armário" são alternativas utilizadas por muitos gays e lésbicas para fugir da "pedagogia do insulto".

Toda forma de discriminação interfere nas expectativas de sucesso e rendimento escolar ${ }^{13}$, produz intimidação, insegurança, estigmatização, segregação, isolamento, estimula a simulação para ocultar a diferença, gera desinteresse pela escola, produz abandono e evasão, tumultua o processo de configuração e expressão identitária, entre outros efeitos. Rogério Junqueira (2009) afirma também que tais dificuldades tendem a ser ainda maiores se pessoas homoeróticas, com identidade ou expressão de gênero consideradas fora do padrão convencional, forem pobres, iletrados, negros, indígenas, soropositivos, tiverem deficiência física ou mental ${ }^{14}$, e não puderem (ou não quiserem) “[...] manter um estilo de vida sintonizado com a celebração hedonista do 'ser jovem' e ter um 'corpo sarado"' (JUNQUEIRA, 2009, p. 25)

Outro tipo de violência pode ser verificado nas imagens e textos subliminares utilizados em livros didáticos e paradidáticos. É recorrente verificar a ausência da figura da mulher ou esta sendo caracterizada como menos qualificada que o homem. Acreditamos que essa escolha contribui para a reprodução de uma imagem de inferioridade feminina, por um lado, e de superioridade masculina, por outro (CARRARA et al., 2009).

Observamos que, em geral, a escola pública se distancia de sua "função social" (MENDONÇA, 2011), que é a socialização e a produção de conhecimento, e reproduz padrões sociais, perpetua concepções, valores e clivagens sociais, "fabrica sujeitos" (seus corpos e identidades $)^{16}$, legitima relações de poder, hierarquias e processos de

\footnotetext{
${ }^{13}$ Sobre isso, ver Marília Carvalho (2008) e Sérgio Carrara et at. (2009).

14 “Capacitismo é a concepção presente no social que lê as pessoas com deficiência como não iguais, menos aptas ou não capazes para gerir as próprias vidas. [...] A deficiência para o capacitista é um estado diminuído do ser humano" (DIAS, 2013, p. 2). Sobre "corporatividade", capacitismo, acessibilidade e outros temas relacionados, ver entrevista com a antropóloga Anahi Guedes de Mello. Disponível em: <https://soundcloud.com/felipe-bruno-guarani-kaiow/g-nero-defici-ncia-e>.

${ }^{15}$ Kimberly Crenshaw (2002) sugere o uso do conceito de interseccionalidade, a fim de capturar os aspectos estruturais e dinâmicos da interação entre dois ou mais eixos da subordinação. A partir deste uso, pode-se pensar como o racismo, sexismo e homofobia criam desigualdades que posicionam social e politicamente alguns grupos.

${ }^{16}$ Noção inspirada especialmente em Michel Foucault (LOURO, 1997).
} 
acumulação, estimula a internalização do heterossexismo, recorrentemente definido como homofobia $^{17}$, misoginia ${ }^{18}$, negação, autoculpabilização, autoaversão de jovens e adultos com identidades e desejos sexuais não hegemônicos. Muitas vezes isso ocorre com a participação ou a omissão da família ${ }^{19}$, da comunidade escolar, da sociedade em geral e do Estado. Admitir esse processo é o primeiro passo para uma desestabilização dessas lógicas e compromissos.

De forma resumida, é possível afirmar que a escola está permeada de conflitos e contradições. Ao mesmo tempo em que transmite e constrói conhecimento, reproduz padrões sociais dominantes, promove o encontro e produz diferenças, distinções e desigualdades nos e entre sujeitos sociais, especialmente estudantes, mas também entre profissionais da educação. Ela se apresenta também como espaço para experiências e relações assimétricas, estímulo para valores hegemônicos, repressões e opressões sobre padrões não hegemônicos, exercícios de poder, conflitos e violências, as quais nem sempre são penalizadas. As violências vivenciadas no ambiente escolar impõem aos estudantes graves consequências pessoais, como danos físicos, traumas, sentimentos de medo e insegurança, além de sentimento de insatisfação.

Diante disso, nos perguntamos: a escola pública pode ser espaço para questionamento dos padrões hegemônicos, estímulo para práticas inclusivas e respeitosas e reflexões teórico-metodológicas?

\section{Formação de profissionais de educação e estudantes para a diversidade}

A partir de um conjunto de fatores históricos e políticos e tendo como foco questões de gênero, sexualidade e étnico-raciais, observou-se no Brasil, a partir de 2003, a criação de secretarias especiais em nível federal, inúmeras políticas públicas, algumas bastante progressistas, políticas de ações afirmativas, leis de combate às violências raciais e sexistas, aprovação de leis para casamento e filiação entre pessoas do mesmo sexo,

\footnotetext{
${ }^{17}$ Heterossexismo é a atitude de discriminação, negação, estigmatização ou ódio contra toda sexualidade não heterossexual. Essa atitude está fundamentada na noção de que a heterossexualidade é superior e mais desejável do que as demais formas de orientação sexual. Sobre essa noção, ver Daniel Borrillo (2009) e Fernando Pocahy (2007).

${ }^{18}$ Sentimento de repulsa ou aversão às mulheres, recorrentemente confundido com machismo.

${ }^{19}$ Sobre homofobia familiar, consultar Sarah Schulman (2010).
} 
entre outros avanços ${ }^{20}$. Foram criados programas nacionais de formação continuada para educadoras/es em gênero e diversidade (sexual, étnico-racial) na escola (GDE), antihomofobia (como o Programa de Combate à Violência e à Discriminação Contra LGBT e de Promoção da Cidadania Homossexual chamado "Brasil sem Homofobia"), entre outras iniciativas como a criação do "Prêmio Construindo a Igualdade de Gênero" (para estudantes de ensino médio, escolas e professores/as), criação de novas universidades, centros e institutos federais, cursos de graduação e pós-graduação especiais para educadores e educadoras.

Essa nova perspectiva normativa e estatal possibilitou a realização de inúmeros projetos visando o questionamento de práticas discriminatórias nas escolas e fora delas e a criação de políticas educacionais voltadas para o reconhecimento da diversidade cultural, a promoção da igualdade de todos e todas e o enfrentamento de todas as formas de discriminação. Possibilitou, ainda, a realização de formação de estudantes de diferentes níveis de ensino (pré-escolar, fundamental, médio e universitário), de profissionais da educação e de lideranças que atuam no fortalecimento do respeito e valorização da diversidade. É o que se observa nos projetos desenvolvidos sob nossa coordenação, entre 2009 e 2016, na Universidade Federal de Santa Catarina (UFSC) e na Universidade da Fronteira Sul (UFFS): curso "Gênero e Diversidade na Escola" (GDE/SECADI); “Projeto Papo Sério” (NIGS/PROEXT); Programa de Iniciação à Docência em Ciências Sociais (PIBID/CAPES) e cursos vinculados ao Programa Pró-Equidade de Gênero.

\section{Gênero e Diversidade na Escola (GDE)}

O curso "Gênero e Diversidade na Escola" (GDE) foi uma experiência pioneira na formação de profissionais da educação básica da rede pública de ensino do Brasil. Focado nas temáticas de gênero, orientação sexual e relações étnico-raciais, foram oferecidos cursos de aperfeiçoamento e especialização nas modalidades de educação presencial e a distância, visando capacitar profissionais para atuarem na educação formal e em instituições promovendo a igualdade e equidade.

\footnotetext{
20 Para uma reflexão sobre este processo histórico, ver especialmente Felipe Fernandes (2011), André Musskopf (2013) e Luiz Lopes (2008).
} 
Em Santa Catarina, foram realizadas pelo Instituto de Estudos de Gênero (IEG) da Universidade Federal de Santa Catarina (UFSC) duas edições de cursos de aperfeiçoamento e uma edição do curso de especialização em Gênero e Diversidade na Escola. O primeiro curso de aperfeiçoamento em $\mathrm{GDE}^{21}$ foi realizado entre março e junho de 2009, em dez cidades-polo ${ }^{22}$ e recebeu a inscrição de quinhentas/os profissionais da educação vinculadas/os a diversas redes públicas de ensino ${ }^{23}$. A segunda edição do curso GDE foi realizada em cinco cidades-polo de Santa Catarina ${ }^{24}$, entre outubro de 2012 e junho de 2013, e ofereceu trezentas vagas ${ }^{25}$.

O curso de especialização em GDE com 420 horas foi realizado nos anos de 2015 e 2016 em cinco cidades-polo ${ }^{26}$ e recebeu a inscrição de duzentas/os profissionais de instituições públicas e ONGs de Santa Catarina ${ }^{27}$.

Segundo Mareli Graupe e Miriam Grossi (2014), o curso em GDE promoveu um espaço para a discussão coletiva sobre gênero, sexualidade e homofobia nas escolas com professoras, professores e estudantes catarinenses. O estudo de gênero no contexto escolar possibilitou "[...] entender que nascemos e vivemos em tempos, lugares e circunstâncias diferentes e específicas e, também, que existem muitas formas de definir e viver a feminilidade e a masculinidade" (GRAUPE; GROSSI, 2014, p. 30). Estudar gênero não significa apenas considerar o olhar sobre as mulheres, “[...] mas privilegiar as relações de poder entre cisgêneros, trans, gays e lésbicas e diversas outras formas sociais e culturais que os constituem como 'sujeitos humanos"”.

\footnotetext{
${ }^{21}$ Com carga horária total de 200 horas, sendo 180 horas a distância (EAD) e 20 horas presenciais.

${ }^{22}$ Blumenau, Braço do Norte, Canoinhas, Chapecó, Concórdia, Florianópolis, Itajaí, Itapema, São José, Videira.

${ }^{23}$ Curso coordenado por Carla Giovanna Cabral, Luzinete Simões Minella, Miriam Pillar Grossi e Mara Coelho de Souza Lago. Maiores informações sobre essa edição, ver Luzinete Minella e Carla Cabral (2009).

${ }^{24}$ Florianópolis, Itapema, Palmitos, Pouso Redondo e Praia Grande.

${ }^{25}$ Sob a coordenação de Miriam Pillar Grossi, Mareli Eliane Graupe e Olga Regina Zigelli Garcia. Maiores detalhes sobre essa edição, ver Mareli Graupe e Miriam Grossi (2014).

${ }^{26}$ Itapema, Florianópolis, Laguna, Palmitos, Praia Grande e Concórdia.

${ }^{27}$ Sob a coordenação de Miriam Pillar Grossi e Olga Regina Zigelli Garcia. Mais detalhes sobre essa edição podem ser encontrados em: <https://ead.ufsc.br/generoediversidadenaescola/apresentacao-do-curso/>. Acesso em: ago. 2016.
} 


\section{Projeto Papo Sério}

O “Projeto Papo Sério" iniciou em 2007 e se tornou a principal ação de extensão na área de gênero e sexualidades do Núcleo de Identidades de Gênero e Subjetividades $(\mathrm{NICS})^{28}$ da Universidade Federal de Santa Catarina (UFSC) ${ }^{29}$. O objetivo principal desse projeto foi problematizar as representações de gênero e sexualidade com estudantes, professores/as e outros profissionais de escolas públicas da Grande Florianópolis ${ }^{30}$. Ele foi desenvolvido em três subprojetos: “Oficinas Papo Sério”, "Concurso de Cartazes sobre Homo-Lesbo-Transfobia e Heterossexismo nas Escolas" e "Iniciação Científica Júnior" (PIBIC EM). Desde o seu início, esses projetos envolveram e impactaram milhares de jovens e profissionais da educação.

As oficinas do "Projeto Papo Sério", planejadas a partir da demanda das escolas, visavam sensibilizar a comunidade escolar para as relações de gênero e seus desdobramentos no ambiente escolar e foram feitas com o intuito de estimular a criação de espaços para formação integral de estudantes, incluindo temas transversais no cotidiano escolar. Elas se constituíam de propostas de ação e discussão de temas polêmicos como homossexualidades, transexualidades, violências de gênero, feminismo, direitos reprodutivos e outros temas demandados pelas escolas, a fim de suprir a falta de discussões sobre estas questões no espaço escolar. Organizadas em regime de “mutirão”, um grupo de quinze (15) pesquisadoras do NIGS, composto por pósdoutorandas, doutorandas, mestres e estudantes de graduação, se dispunha a fazer inumeras oficinas simultâneas durante um ou dois turnos escolares. Assim, a realização de oficinas tornava-se um "evento" nas escolas, mobilizando todo o espaço escolar em torno das questões abordadas. Atividade extremamente provocativa, as oficinas permitiam assim uma dupla formação no campo dos estudos de gênero e sexualidade: de

\footnotetext{
${ }^{28}$ O NIGS realiza ações de ensino, pesquisa e extensão desde 1991; é coordenado pela professora Miriam Pillar Grossi, está vinculado ao Laboratório de Antropologia (LAS) e ao Programa de Pós-Graduação em Antropologia Social (PPGAS) da Universidade Federal de Santa Catarina (UFSC). Mais informações sobre o NIGS, ver: <www.nigs.ufsc.br>.

${ }^{29}$ O "Projeto Papo Sério" recebe apoio da Pró-Reitoria de Pesquisa e Extensão da UFSC (PRPE), do Programa de Extensão Universitária (PROEXT), do Ministério da Educação (MEC) e do CNPq, por meio do Programa Institucional de Bolsas de Iniciação Científica Júnior. Reflexões sobre esse projeto podem ser encontradas em Mareli Graupe et al. (2011), Arianna Sala e Miriam Grossi (2013).

30 A Grande Florianópolis é uma área geográfica composta pelos seguintes municípios: Florianópolis, São José, Biguaçu, Antônio Carlos, Palhoça, Santo Amaro da Imperatriz, Governador Celso Ramos, São Pedro de Alcântara e Águas Mornas.
} 
um lado estudantes do ensino básico de escolas públicas que eram convidados a refletir sobre temas do cotidiano raramente abordados na escola; de outro, estudantes universitárias/os que tinham a oportunidade de "aplicar" os conhecimentos teóricos recebidos no espaço acadêmico no ambito da escola.

Entre 2009 e 2015, o NIGS realizou o Concurso de Cartazes sobre Homo-LesboTransfobia e Heterossexismo nas Escolas com o objetivo de problematizar as representações de gênero e sexualidade com jovens estudantes de escolas públicas da Grande Florianópolis. Centenas de escolas e milhares de estudantes e profissionais da educação foram envolvidas/os nas sete edições deste concurso ${ }^{31}$.

O Programa Institucional de Bolsas de Iniciação Científica no Ensino Médio (PIBIC EMICNPq) foi realizado no NICS entre outubro de 2010 e fevereiro de 2012 como parte do "Projeto Papo Sério"32 e envolveu dez estudantes ( 3 meninas e 7 meninos) de escolas públicas da Grande Florianópolis, com idade entre 14 e 18 anos. Esse projeto, inovador no campo da formação de jovens estudantes de instituições públicas, introduziu estes estudantes de ensino médio em atividades de iniciação científica no campo da Antropologia e dos Estudos de Gênero e Sexualidade, quando tiveram oportunidade de participar de grupos de estudos, de atividades de formação, de eventos científicos e de projetos coletivos - inclusive como autoras e autores, entre outras atividades ${ }^{33}$.

A partir dessa experiência, foi desenvolvido, de forma pioneira, na Universidade Federal da Fronteira Sul (UFFS), entre 2013 e 2014, o projeto “Antropologia, Educação e Diversidade - Iniciação Científica no Ensino Médio"34, com o objetivo de fortalecer o processo de disseminação das informações e conhecimentos científicos e tecnológicos básicos, bem como desenvolver atitudes, habilidades e valores necessários à educação científica e tecnológica. Esse projeto envolveu dez estudantes (oito meninas e dois meninos com idade entre 14 e 17 anos) do ensino médio de quatro escolas públicas da

\footnotetext{
${ }^{31}$ Os editais, informações, produções e repercussões sobre sete concursos podem ser encontrados em: <http://nigs.ufsc.br/concurso-de-cartazes/> e em: <http://concursonigs.paginas.ufsc.br/>.

32 Atuaram na coordenação desse projeto: Miriam Pillar Grossi, Tânia Welter e Anelise Fróes da Silva. Informações sobre esse projeto, ver Grossi et al. (2012).

33 Dados disponíveis em Miriam Grossi et al. (2012).

34 Projeto financiado pelo Programa Institucional de Bolsas de Iniciação Científica no Ensino Médio (PIBICEM/CNPq) e coordenado por Tânia Welter e Maria Alice Canzi Ames. Mais informações sobre o projeto, ver Welter, Lewer e Ames (2017).
} 
Rede Estadual de Ensino de Santa Catarina, município de Chapecó (SC), além de estudantes e professoras da Universidade Federal da Fronteira Sul, campus Chapecó.

Após seleção através de edital público, estudantes do ensino médio bolsistas de Iniciação Científica Júnior (ICJ/CNPq) foram inseridos em espaços acadêmicos e orientados em atividades semanais de formação científica. Tiveram oportunidade e foram estimulados a organizar, coordenar e participar de eventos, aulas, oficinas, grupo de estudos e cursos; elaborar projetos; realizar pesquisas empíricas e bibliográficas; elaborar e apresentar relatórios, artigos, comunicações; participar de viagens de estudos e intercâmbio, entre outras atividades. Embora o projeto não fosse exclusivo de formação em gênero e sexualidade, a incorporação dessas problemáticas em quatro de cinco projetos de pesquisa ${ }^{35}$ é uma demonstração do impacto dessa formação entre bolsistas PIBIC-EM da UFFS.

Por fim, é possível afirmar que esses e essas jovens estudantes de escolas públicas da Grande Florianópolis e de Chapecó e bolsistas ICJ da UFFS e UFSC foram impactados e empoderados quando tiveram acesso à universidade e ao conhecimento científico produzido sobre gênero e sexualidades. Esses projetos e o ambiente acadêmico lhes possibilitaram desconstruir normatividades, produzir novos saberes e impactar outras pessoas e instituições.

\section{Programa de Iniciação à Docência em Ciências Sociais}

O Programa Institucional de Bolsas de Iniciação à Docência (PIBID/CAPES) objetiva oportunizar e estimular a docência nos cursos de licenciatura ${ }^{36}$. O PIBID Ciências Sociais da Universidade Federal da Fronteira Sul, campus Chapecó, foi realizado entre agosto de

\footnotetext{
35 Dentro de um leque ilimitado de temas, os/as bolsistas deste projeto escolheram os seguintes temas de pesquisa: "Homofobia na EEB Marechal Bormann", "O corpo feminino na visão das estudantes da EEB Marechal Bormann", "A importância da família na vida dos estudantes da escola EEB Coronel Ernesto Bertaso", "Violências na escola na visão de estudantes - um estudo de caso".

36 Programa financiado pela Coordenação de Aperfeiçoamento de Pessoal de Nível Superior (Capes), Ministério da Educação do Brasil (MEC).
} 
2012 e fevereiro de 2014, na Escola de Educação Básica Marechal Bormann, em Chapecó, e envolveu quatorze estudantes do curso de Licenciatura em Ciências Sociais ${ }^{37}$.

Com objetivo de problematizar questões de gênero e sexualidade com estudantes de ensino médio de escolas públicas de Chapecó, o grupo de PIBID de Ciências Sociais propôs e realizou os seguintes projetos: "Relações Afetivas na Escola", "Gincana Sociológica” e "Oficina Gênero e Sexualidade”.

Observou-se que os projetos impactaram todas as pessoas e instituições envolvidas: estudantes, professoras/es e profissionais da educação (básica e superior). 0 uso combinado de recursos didáticos diversos (aula expositiva dialogada, debate, teatro, oficina, produção de mídia) facilitou o processo de formação de estudantes e profissionais da educação, e os ajudou refletir e fazer vínculos entre teoria e vivência/observação de ações violentas e discriminatórias diante da orientação sexual e identidade, expressão e performance de gênero divergente da norma; pertença a religiões não católicas; residência em bairros estigmatizados; pertencimento a etnias/grupos ou com cor de pele não brancas; pertencimento a famílias não nucleares, heterossexuais ou monogâmicas.

Concluiu-se que a reflexão sobre as questões de gênero e sexualidade deve ser mais frequente na escola e nas aulas de Sociologia/Ciências Sociais, e a escola não deve reproduzir, compactuar ou silenciar diante de ações violentas e discriminações; deve, antes, ser o espaço de reflexões, produção de novos saberes e de contribuição na construção de políticas públicas e relações que respeitem e valorizem a diferença entre as pessoas.

Por fim, contrariando recorrentes discursos de que a escola é o espaço que reproduz e revela preconceitos, produz violências e assimetrias, o sucesso obtido nesses projetos indicou que a escola pode ser o espaço de reflexão e repúdio às violências, de produção de conhecimentos e estímulo à construção de relações igualitárias e respeitosas diante da diversidade também de gênero e sexual.

\footnotetext{
37 Projeto coordenado por Tânia Welter e Tarcísio Brighenti. Para conhecer mais sobre este projeto, ver Welter e Brighenti (2017).
} 


\section{Impactos da formação em gênero e sexualidade}

A partir dos relatórios e depoimentos orais, observou-se que os projetos PIBIC-EM, PIBID Ciências Sociais e GDE realizados nas universidades públicas de Santa Catarina (Brasil), entre 2009 e 2016, impactaram estudantes, profissionais e instituições educacionais. Os projetos oportunizaram a estudantes (do ensino médio, da graduação e da pós-graduação) e a profissionais da educação atuantes em escolas públicas de Santa Catarina contato com conteúdos teórico-metodológicos, conhecimentos científicos, realização de formação científica e docente, contato com profissionais e especialistas, aproximação entre diferentes instituições de ensino (educação básica e ensino superior), contato entre estudantes e diferentes realidades escolares, realização de socializações, participação e organização de eventos científicos, cursos, viagens e intercâmbios, realização de pesquisas científicas, desenvolvimento de habilidades individuais e elaboração e socialização de produções textuais. Os projetos impactaram e fortaleceram também as instituições de ensino superior e da educação básica pela presença física de estudantes e profissionais da educação e realização de atividades diversificadas.

Diversos estudantes e profissionais da educação afirmaram que foi a primeira vez que tiveram contato com reflexões teóricas, com pesquisadores/as e puderam refletir sobre gênero e sexualidade. Participar de projetos de iniciação científica estimulou a reflexão teórica sobre as violências, especialmente sexistas e heterossexistas, a revisão de pré(conceitos), denúncia de violências praticadas dentro e fora de ambientes educacionais e engajamento em projetos visando o enfrentamento das violências e valorização da diversidade. A participação na elaboração da Cartilha de Prevenção às Violências Sexistas, Homofóbicas e Racistas nos Trotes Universitários, cuja primeira edição data de 2011, mas que foi aprimorada e reeditada nos anos seguintes, na participação e premiação no Concurso de Cartazes sobre Homo-Lesbo-Transfobia e Heterossexismo nas Escolas e no Prêmio Construindo a Igualdade de Gênero ${ }^{38}$ (KREMER, 2013), exemplificam a mobilização de estudantes de ensino médio e bolsistas ICJ.

Observamos que, embora haja previsão legal, grande parte das professoras e especialistas não trabalha com conteúdos de gênero e sexualidade na escola. É

${ }^{38}$ Organizado pela Secretaria de Políticas para as Mulheres (SPM/PR), o Conselho Nacional de Desenvolvimento Científico e Tecnológico (CNPq/MCTI), o Ministério da Educação (MEC) e a ONU Mulheres. 
recorrente também observar a postura de silenciamento diante de ações discriminatórias praticadas na escola ou fora dela. Durante as formações em gênero e sexualidade realizadas, foram recorrentes manifestações de surpresa, interesse e percepções baseadas no senso comum por parte de profissionais da educação e de estudantes de ensino médio e da graduação.

\section{Considerações finais}

Sabemos que escolas e universidades são espaços contraditórios, onde se reproduzem hierarquias e assimetrias, promovem-se violências ou compactua-se com elas, silencia-se e insiste-se em modelos normativos. Todavia, é também nesses espaços que se tem produzido um importante movimento de transformação social, marcado pela busca crescente de formação de professores/as e estudantes nas temáticas de gênero e sexualidade. Assim, um dos principais desafios da formação em gênero e sexualidade é sensibilizar as pessoas a uma perspectiva crítica sobre as relações sociais naturalizadas pela dominação, exclusão e discriminação. Essa sensibilização se dá, via de regra, pela “descoberta” das pessoas em formação de situações de seus cotidianos e de relações pessoais marcadas por violências das mais diferentes ordens: dupla ou tripla jornada de trabalho, relações conjugais e familiares hierárquicas, sexismo, misoginia, capacitismo, racismo, homo-lesbo-transfobia. Mais do que categorias teóricas, gênero e sexualidade quando abordados de forma interseccional, dizem respeito a experiências, práticas e subjetividades de "sujeitos sociais" realizadas em relações coletivas.

Constatamos que a participação nos projetos e curso de formação possibilitou a alguns/mas rever conceitos, mudar comportamentos, desnaturalizar, refletir, socializar, dialogar sobre normas e preconceitos. Percebeu-se também que algumas pessoas foram empoderadas e se fortaleceu o movimento de resistências contra discriminações (homolesbo-transfobia, sexista, heterossexista, machista, racista, capacitista e social), contra o exercício de pedagogias “do insulto" (JUNQUEIRA, 2009), dos "gêneros hegemônicos” (BENTO, 2011), “da intolerância” (BENTO, 2011), contra os silenciamentos a respeito da diversidade nos livros, políticas e pedagogias (LIONÇO; DINIZ, 2009), a favor da aceitação e visibilização da diversidade (BENTO, 2011). 
O contexto político no qual escrevemos a última versão deste artigo, em novembro de 2016, é radicalmente diferente do contexto no qual desenvolvemos os projetos aqui relatados. Um golpe de Estado parlamentar retirou a presidenta eleita com 54 milhões de votos, Dilma Rousseff, da presidência da República. Desde abril de 2016, os ministérios direcionados à políticas da igualdade, como a Secretaria de Políticas para Mulheres, de Questões Étnico-Raciais e Direitos Humanos, assim como a SECADI Secretaria do MEC responsável por políticas de diversidade na escola, foram extintos. Movimentos mundiais, como o iniciado no Vaticano, contra uma suposta "ideologia de gênero" que estaria sendo praticada por teorias e movimentos feministas e queer, também se manifestaram no Brasil, inclusive no âmbito da UFSC através de artigo no Boletim da Associação dos professores (APUFSC). Na sequência destas reações, deputados brasileiros entraram com um projeto de lei defendendo uma "escola sem partido", projeto que nada mais é do que uma forma de cercear a liberdade de expressão e a formação critica de estudantes.

Os exemplos concretos de formação de professoras/es e estudantes nesse campo mostraram as potencialidades e desafios dessa formação para a transformação das relações sociais marcadas por diferentes violências. Todavia, lamentamos que mesmo sabendo o quanto é necessário e urgente ampliar e fortalecer projetos e ações de formação em gênero e sexualidade (institucionais ou não) e políticas públicas que promovam a equidade e liberdade, esta não é mais uma política de Estado no Brasil. Sabemos que somente uma sólida formação escolar e universitária a respeito de gênero, sexualidade e diversidade possibilitará repudiar e criminalizar atos discriminatórios contra sujeitos que não se adequam às normas sociais vigentes e/ou que fazem parte de grupos historicamente discriminados. 


\section{Referências}

BENTO, Berenice. Na escola se aprende que a diferença faz a diferença. Revista Estudos Feministas, Florianópolis, v. 19, n. 2, maio/ago. 2011.

BORRILLO, Daniel. A homofobia. In: LIONÇO, Tatiana; DINIZ, Débora. (Orgs.). Homofobia \& educação: um desafio ao silêncio. Brasília/DF: Letras Livres, 2009. p. 15-46.

CANDAU, Vera. Multiculturalismo e educação: desafios para a prática pedagógica. In: MOREIRA, A. F.; CANDAU, V. M. (Orgs.). Multiculturalismo: diferenças culturais e Práticas Pedagógicas. Petrópolis: Vozes, 2008. p.13-37.

CARRARA, Sérgio L. et al. (Orgs.). Gênero e diversidade na escola: formação de professoras/es em gênero, orientação sexual e relações étnico-raciais. Livro de Conteúdos. Versão 2009. Rio de Janeiro/Brasília: CEPESC/SPM, 2009.

CARVALHO, Marília P. de. Gênero na sala de aula: a questão do desempenho escolar. In: MOREIRA, A. F.; CANDAU, V. M. (Orgs.). Multiculturalismo: diferenças culturais e práticas pedagógicas. Petrópolis: Vozes, 2008. p. 90-124.

CRENSHAW, Kimberly. Documento para o encontro de especialistas em aspectos da discriminação racial relativos ao gênero. Revista Estudos Feministas, Florianópolis, ano 10, v. 1, p. 171-188, 2002.

DEBERT, Guita G.; OLIVEIRA, Marcella B. Os modelos conciliatórios de solução de conflitos e a 'violência doméstica'. Cadernos Pagu, Núcleo de Estudos de Gênero-Pagu/Unicamp, Campinas, v. 29, p. 305-337, 2007.

DIAS, Adriana. Por uma genealogia do capacitismo: da eugenia estatal a narrativa capacitista social. In: SIMPÓSIO INTERNACIONAL DE ESTUDOS SOBRE A DEFICIÊNCIA SEDPCD/Diversitas/USP Legal, 1., 2013, São Paulo, SP, Anais... São Paulo, SP: USP, 2013.

\section{FERNANDES, Felipe B. M. A agenda anti-homofobia na educação brasileira (2003-}

2010). 2011. 422 p. Tese (Doutorado em Ciências Humanas) - Programa de PósGraduação Interdisciplinar em Ciências Humanas, Universidade Federal de Santa Catarina, Florianópolis 2011.

FONSECA, Claudia. Preparando-se para a vida: reflexões sobre escola e adolescência em grupos populares. Em Aberto, Brasília, ano 14, n. 61, jan./mar. 1994.

FLEURI, Reinaldo M. Educação Intercultural: decolonializar o poder e o saber, o ser e o viver. Visão Global, Joaçaba, v. 15, n. 1-2, p. 7-22, jan./dez. 2012.

FLEURI, Reinaldo M. (Org.). Intercultura e movimentos sociais. Florianópolis: MOVER/NUP, 1998. 
GRAUPE, Mareli E. et al. Projeto de extensão "Papo Sério": Realização de oficinas sobre gênero, sexualidade e homofobia com jovens das escolas públicas da grande Florianópolis. In: V SEMINÁRIO CORPO, GÊNERO E SEXUALIDADE: ESTÂNCIAS E PRÁTICAS DE PRODUÇÃO NAS POLÍTICAS DA PRÓPRIA, I SEMINÁRIO INTERNACIONAL CORPO, GÊNERO E SEXUALIDADE, I ENCONTRO GÊNERO E DIVERSIDADE NA ESCOLA, 2011, Rio Grande, RS. Anais... Rio Grande, RS: FURG, 2011. p. 1516-1518.

GRAUPE, Mareli E. ; GROSSI, Miriam P. Superando obstáculos: a implementação do GDE em Santa Catarina. In: GARCIA, Olga R. Z.; GROSSI, Miriam P.; GRAUPE, Mareli E. (Orgas.). Gênero e Diversidade na Escola: desafios da formação em gênero, sexualidades e diversidades étnico-raciais em Santa Catarina. Tubarão: Copiart, 2014. p. 13-31.

GROSSI, Esther P.; BORDIN, Jussara (Org.). Paixão de aprender. Petrópolis: Vozes, 2009.

GROSSI, Esther P. Agressividade: qual o teu papel na aprendizagem? Porto Alegre, GEEMPA, 2009.

GROSSI, Miriam P. Identidade de Gênero e Sexualidade. Antropologia em primeira mão, Florianópolis, n. 24, p. 1-17, 2010. Edição revisada.

GROSSI, Miriam P. et al. Relatório final projeto papo sério: iniciação científica no ensino médio. Florianópolis: UFSC/CFH/Núcleo de Identidades de Gênero e Subjetividades, 2012.

JESUS, Jaqueline G. Orientações sobre identidade de gênero: conceitos e termos. 2. ed. ver. amp. Brasília, e-book, 2012. Disponível em: <http://www.sertao.ufg.br>. Acesso em: ago. 2016.

JUNQUEIRA, Rogério. D. Homofobia nas escolas: um problema de todos. In: JUNQUEIRA, R. D. (Org.). Diversidade sexual na educação: problematizações sobre homofobia nas escolas. Brasilia: UNESCO/MEC, 2009. p. 13-51.

KREMER, Natan S. O Crime do Professor de Geografia. In: PRÊMIO CONSTRUINDO A IGUALDADE DE GÊNERO, $9^{\circ}$. Redações, artigos científicos e projetos pedagógicos premiados - 2013. Brasília: PR, SPM, 2013. p. 229-232.

LIONÇO, Tatiana; DINIZ, Débora. Qual a diversidade sexual dos livros didáticos brasileiros? In: LIONÇO, Tatiana; DINIZ, Débora. (Orgas.). Homofobia e educação: um desafio ao silêncio. Brasília: Letras Livres, 2009.

LOPES, Luiz P. M. Sexualidades em sala da aula: discurso, desejo e teoria queer. In: MOREIRA, A. F.; CANDAU, V. M. (Orgs.). Multiculturalismo: diferenças culturais e práticas pedagógicas. Petrópolis: Vozes, 2008. p. 125-148.

LOURO, Guacira L. A emergência do gênero. Gênero, sexualidade e educação: uma perspectiva Pós-Estruturalista. Petrópolis: Vozes, 1997. p. 14-36. 
LOURO, Guacira L. Pedagogias da sexualidade. In: LOURO, Guacira Lopes (Org.). 0 corpo educado: pedagogias da sexualidade. Belo Horizonte: Autêntica, 2003. p. 7-34.

MENDONÇA, Sueli G. de Lima. A crise de sentidos e significados na escola: a contribuição do olhar sociológico. Caderno CEDES, Campinas, v. 31, n. 85, p. 341-357, 2011.

MEYER, Dagmar E. Corpo, Violência e educação: uma abordagem de gênero. In: JUNQUEIRA, R. D. (Org.). Diversidade sexual na educação: problematizações sobre homofobia nas escolas. Brasilia: UNESCO/MEC, 2009. p. 213-233.

MINELLA, Luzinete S.; CABRAL, Carla G. Práticas pedagógicas e emancipação: gênero e diversidade na escola. Florianópolis: Editora Mulheres, 2009.

MOREIRA, Antonio F. B.; CÂMARA, Michelle J. Reflexões sobre currículo w identidade: implicações para a prática pedagógica. In: MOREIRA, A. F.; CANDAU, V. M. (Orgs.).

Multiculturalismo: diferenças culturais e práticas pedagógicas. Petrópolis: Vozes, 2008. p. 38-66.

MUSSKOPF, André S. A relação entre diversidade religiosa e diversidade sexual: um desafio para os direitos humanos e o Estado laico. Estudos de Religião, São Bernardo do Campo, v. 27, n. 1, p. 157-176, jan.-jun. 2013.

NÚCLEO DE IDENTIDADES DE GÊNERO E SUBJETIVIDADESINIGS|UFSC. Cartilha de prevenção às violências sexistas, homofóbicas e racistas nos trotes universitários. Florianópolis: UFSC, março de 2011.

NOVO, Arthur L. C. O armário na escola: regimes de visibilidade de professoras lésbicas e gays. 2015. Dissertação (Mestrado em Antropologia Social) - Universidade Federal de Santa Catarina, UFSC, 2015.

NUNES, Virginia de S. C. Antropologia, diversidade sexual e educação: uma experiência etnográfica no ensino público da Bahia. 2015. Dissertação (Mestrado em Antropologia Social) - Universidade Federal de Santa Catarina, Florianópolis, 2015.

ORTNER, Sherry. Poder e projeto: reflexões sobre a agência. In: GROSSI, Miriam Pilar. ECKERT, Cornelia. FRY, Peter (Orgs.). Conferências e diálogos: saberes e práticas antropológicas. Blumenau: Nova Letra, 2007. p. 45-80.

POCAHY, Fernando. Um mundo de injúrias e outras violações: reflexões sobre a violência heterossexista e homofóbica a partir da experiência do CRDH - Rompa o Silêncio. In: POCAHY, F. (Org.). Rompendo o silêncio: homofobia e heterossexismo na sociedade contemporânea. Porto Alegre: Nuances, 2007. p. 10-26.

QUEIROZ, Renato da S. Não vi e não gostei: o fenômeno do preconceito. 6. ed. São Paulo: Moderna, 1997. 
RIFIOTIS, Theophilos. Violência, Justiça e Direitos Humanos: reflexões sobre a judicialização das relações sociais no campo da "violência de gênero". Cadernos Pagu, Campinas, n. 45, p. 261-295, jul./dez. 2015.

ROCHA, Ana Luiza Carvalho da. Entrevista. Revista Nova Escola, 2011. Disponível em: $<$ http://revistaescola.abril.com.br/gestao-escolar/diretor/antropologia-util-escola423101.shtml>. Acesso em: 20 jun. 2014.

SALA, Arianna; GROSSI, Miriam P. Batendo um "papo sério": desconstruindo gênero e sexo nas escolas de Santa Catarina. In: SEMINÁRIO INTERNACIONAL ENLAÇANDO SEXUALIDADES, 3., 2013, Salvador, BA. Anais... Salvador, BA: Universidade do Estado da Bahia, 2013.

SCHULMAN, Sarah. Homofobia Familiar: uma experiência em busca de reconhecimento. Tradução Felipe B. M. Fernandes. Revista Bagoas, Natal: CCHLA, n. 5, p. 67-78, 2010.

WELTER, Tânia; LEWER, Rafael F.; AMES, Maria Alice C. Reflexões sobre os desafios e experiências do projeto de iniciação científica no ensino médio da UFFS, Santa Catarina. In: WELTER, Tânia; GROSSI, Miriam P.; GRAUPE, Mareli E. (Org.). Antropologia, Gênero e Educação em Santa Catarina. Tubarão: Copiart/Florianópolis: Editora Mulheres, 2017.

WELTER, Tânia; BRIGHENTI, Tarcisio. Reflexões sobre experiências de ensino em Ciências Sociais na educação básica em Chapecó, Santa Catarina. In: WELTER, Tânia; GROSSI, Miriam P.; GRAUPE, Mareli E. (Org.). Antropologia, Gênero e Educação em Santa

Catarina. Tubarão: Copiart/Florianópolis: Editora Mulheres, 2017.

Universidade do Estado de Santa Catarina - UDESC Programa de Pós-Graduação em Educação - PPGE Revista Linhas Volume 19 - Número 39 - Ano 2018 revistalinhas@gmail.com 